\title{
Activité masticatoire et réduction de la taille des particules de 2 types d'ensilages chez des ovins et des bovins
}

\author{
EH Amouche, AG Deswysen \\ Université cathologique Louvain, Fac Sci Agr, unité de génétique, place Croix-du-Sud, 2 (bte 14), \\ 1348 Louvain-la-Neuve, Belgique
}

Douze agnelles de race Texel, âgées de 6 à 7 mois $(34 \pm 4 \mathrm{~kg})$ et 6 génisses de race HolsteinFriesian, ágées de 19 à 24 mois $(427 \pm 42 \mathrm{~kg}$ ), reçurent à volonté ( $9 \mathrm{~h}$ et $16 \mathrm{~h}) 2$ ensilages à brins courts : herbe préfanée $(2,2 \mathrm{~cm})$ et maïs $(1,1 \mathrm{~cm})$, selon un schéma expérimental en crossover $(2 x$ $2 \times 12$ et $2 \times 2 \times 6$ ). Les rations furent supplémentées journalièrement avec $100 \mathrm{~g}$ de tourteau de soja $+30 \mathrm{~g}$ de CMV pour les moutons et $500 \mathrm{~g}$ de tourteau de soja $+100 \mathrm{~g}$ de CMV pour les génisses. Les ensilages d'herbe et de maïs présentaient respectivement les teneurs suivantes : 45,0 et $30,8 \%$ MS, 10,6 et $9,3 \%$ MAT, 63,0 et $50,5 \%$ NDF, 38,6 et $26,3 \%$ ADF. Les animaux furent soumis à une luminosité contrôlée : $12 \mathrm{~h}$ de lumière et $12 \mathrm{~h}$ d'obscurité, durant toute l'expérimentation. Celle-ci consista en 1 période préexpérimentale de $25 \mathrm{j}$ pour les moutons et $18 \mathrm{j}$ pour les génisses, et 2 périodes expérimentales de $25 \mathrm{j}$. L'enregistrement en continu des mouvements de mâchoires ainsi que le prélèvement rectal ponctuel (à $8 \mathrm{~h} 30-9 \mathrm{~h}$ ) de fèces furent réalisés du $15^{\circ}$ au $18^{\circ}$ jour de chaque période expérimentale. La dimension moyenne des particules fécales (DMPF) fut déterminée par tamisage sous eau.
Chez les ovins et les bovins, l'ingestion volontaire d'ensilage de maïs est supérieure à celle d'ensilage d'herbe préfanée $(P<0,05)$ et les durźes unitaires d'ingestion, de rumination et de mastication sont plus faibles $(P<0,04)$, entrainant partiellement une DMPF supérieure avec l'ensilage de maïs spécialement chez les génisses $(P<0,004 ;$ tableau $\mathrm{I})$. La durée moyenne d'un cycle de rumination n'est pas affectée par le type d'ensilage. Les activités unitaires de mastication sont supérieures $(P<0,05)$ chez les agnelles et $c e$ pour un niveau d'ingestion volontaire plus faible $(P<0,05)$, entraînant partiellement une DMPF plus faible $(P<0,05)$ chez les agnelles comparées aux génisses, ce qui est en accord avec Thomas et Campling (1977). En outre, la différence de DMPF entre les ensilages d'herbe préfanée et de maïs est nettement plus faible chez les agnelles. Ceci suggère que, par rapport aux bovins, les ovins tolèrent une moindre variation de la taille des particules alimentaires aptes à franchir l'orifice réticulo-omasal.

Thomas S, Campling RC (1977) J Br Grass/ SoC 32,33

Tableau I. Ingestion volontaire journalière (IV), durées unitaires d'ingestion (DUI), de rumination (DUR), de mastication (DUM), durée moyenne d'un cycle de rumination (DMB) et dimension moyenne des particules fécales (DMPF) chez 12 agnelles et 6 génisses recevant à volonté des ensilages d'herbe préfanée et de maïs.

\begin{tabular}{|c|c|c|c|c|c|c|c|c|c|}
\hline \multirow[t]{2}{*}{ Paramètres } & \multicolumn{4}{|c|}{ Agnelles } & \multicolumn{4}{|c|}{ Génisses } & \multirow{2}{*}{$\begin{array}{c}\text { Test de } \\
\text { Studen } \\
\quad \mathrm{P}\end{array}$} \\
\hline & Herbe & Maïs & $E S^{a}$ & $P$ & Herbe & Maïs & $E S^{a}$ & $\mathbf{P}$ & \\
\hline IV (gMS/kg & 39,7 & 53,2 & 1,7 & 0,0001 & 81,3 & 88,0 & 2,4 & 0,05 & $<0,05$ \\
\hline DUI (min/gMS/kgo,75) & 7,3 & 5,9 & 0,4 & 0,004 & 4,8 & 4,1 & 0,2 & 0.04 & $<0,0$ \\
\hline DUR (min/gMS/kgo,75) & 13,2 & 9,8 & 0,2 & 0,0001 & 6,4 & 5,2 & 0,5 & 0,02 & $<0,05$ \\
\hline DUM (min/gMS/kg0,75) & 20,5 & 15,8 & 0,4 & 0,0001 & 11,2 & 9,3 & 0,3 & 0,005 & $<0,05$ \\
\hline DMB (min) & 0,79 & 0,82 & 0,03 & 0,25 & 0,86 & 0,87 & 0,02 & 0,62 & $<0,05$ \\
\hline $\operatorname{DMPF}(\mu \mathrm{m})$ & 159 & 207 & 7,5 & 0,0002 & 235 & 346 & 16,7 & 0,004 & $<0,05$ \\
\hline
\end{tabular}

a Erreur standard de la difference entre les 2 traitements. 